\title{
Teacher Training Project \\ An Attempt to Devise an In-service Training \\ Programme for English Language Teachers
}

DOI: 10.47050/66515321.238-254

Meretguly Gurbanov

Today, English has attained a different role other than as a second or a foreign language; it has become a primary medium of international communication around the world. The increase in its use leads naturally to a demand for people with a good knowledge of English. As a result, English language teaching (ELT) has become a part of basic education, an important business and a major part of educational policy. Thus, English language teacher training has become an important issue. However, the in-service teacher training programmes that have been employed at various times are often not fully successful in providing systematic opportunities for continuing education, skills and career development. Consequently, continuous teacher education (CTE) has recently regained attention in the field of foreign language teaching (FLT). This revival of interest in teacher development has led researchers, policy makers, and leaders to seek programmes in which teachers could be educated in recent methods of FLT. In this scope, the Ministry of Education of Turkmenistan adopted the Conception of Foreign Language Teaching and Learning (the Conception) in December 2017. Throughout the Conception, a CTE programme for foreign language teachers using national and international experience was highly recommended. This chapter aims to propose an inservice teacher training programme. It also tries to present techniques of conducting CTE as a part of in-service teacher training and suggests ways to implement them for English language teachers.

\section{Keywords:}

\section{conception}

\section{continuous teacher education}

English language teaching

foreign language teaching

in-service teacher training 


\section{Introduction and Background of the Project}

If you give people fish, they will eat for a day; if you teach them how to fish, they will eat for a lifetime.

proverb

By the 1950s, countries around the world had placed an emphasis on English language teaching (ELT) as an important requirement of education (Collins, 2010). Also, in countries where English is not an official language, the importance of English as an international language has been widely recognised. As a result, ELT has become a part of both secondary and tertiary education systems in countries where English is used as a foreign language. In such contexts, teachers face challenges because of school environments (Alibakhshi \& Dehvari, 2015). In such cases, teachers might become frustrated and less effective (Murray, 2010). Therefore, professional development activities can solve some of these problematic issues (Bailey, Curtis \& Nunan, 2001).

In the age of advancement in education, the term 'professional development' (PD) may be used in reference to a wide variety of forms of specialised training, formal education, or advanced professional learning methods intended to help administrators, teachers, and other educators improve their professional knowledge, competences, skills, and effectiveness. When the term is used in education contexts, it may range from a one-day conference to a two-week workshop to multiyear advanced degree programmes. They may be delivered in person, face-to-face or online, during the school day or outside of normal school hours, or through one-on-one interactions or in groups. Participants might even be given a few days or months of official leave. Within this period, teachers' PD has moved beyond a series of simple, in-service workshops and expanded into a more organised system of continuing education. Engaging in PD models shows that one is a lifelong learner who is willing to adapt and make the necessary changes within the professional environment to produce more successful outcomes. In order to have successful outcomes, teachers must continuously evaluate not only their students but also their personal practices within the learning environment. Continuing professional development (CPD) keeps teachers up to date with the latest changes and developments 
in new curriculum resources, teaching methods and techniques and more. The best professional development is continuing, experiential, collaborative and connected to and derived from working with students. Regardless of their roles, teachers should think that there are sets of skills that they need to develop, as there is no boundary to professionalism. Every situation may provide opportunities for the development of teachers. There are many experiences that allow for teacher development, such as career discussions, mentoring, workshops, online learning, debates with colleagues and work shadowing. All of these and more can enable teachers to improve what they do, why they do it and how they do it. CPD is integral to a successful career and impactful research. Identifying teachers' CPD needs can happen as a planned process or spontaneously as a response to deficiencies in teaching skills or knowledge. To help facilitate teachers' learning and develop their skills in these areas, at a time and in a way that suits them, the Turkmen National Institute of Education (NIE), under the Ministry of Education, conducts PD courses for foreign language teachers in various institutions throughout the year. The NIE monitors and checks the feedback on training courses. In December 2017, the Conception of Foreign Language Teaching and Learning (hereinafter 'the Conception') was adopted by the Ministry of Education. Since then, many activities have been carried out. One of the most important activities was a call for a continuous teacher education (CTE) programme, which was repeatedly mentioned throughout the Conception. This programme should include sessions on teacher effectiveness, teacher professionalism, and other important stages of teacher development. This process led to developing an approach to the management of innovation through the present in-service teacher training project. This project aims to propose in-service teacher training programmes using national and international experiences. This would be a combination of local (i.e. Turkmen) experiences with those of teachers from around the world. The current research aims to use the scientific and literary works of national and international scholars to suggest modifications to in-service teacher training programmes. This paper consequently tries to present techniques of conducting CTE that are a combination of national and international experiences and suggests ways to implement this for foreign language teachers. 


\section{Problem statement}

As English is an international language, it has been selected as a compulsory subject for students of all levels. The general goal of teaching English is to equip students with the required level of language to help them communicate effectively and successfully in various situations. The essence of a teacher is to help students to become successful learners. This is why it may be so hard for educators to look at themselves to see what they can improve upon. Teacher training in EFL contexts is quite challenging compared to the same process in the target language community, where preservice teachers' exposure to the language environment is not limited to the institutional setting.

Many teachers often complain because they believe that students are not successful communicators in English. Teachers feel helpless and they wish to change the situation. The present researcher believes that the problem is not because there are no knowledgeable teachers, but rather that it is a problem of teachers' practices. Teachers are, more often than not, spending every minute in class explaining several language items and neglecting the importance of providing students with chances to use the language. They have problems with what to teach, how to teach and why. Therefore, this study will try to deal with these problems and will offer several activities through a wellorganised action plan, as the practical planning of actions is often the more calm and manageable approach in such cases.

\section{Purpose of study}

This project aims to use the scientific and literary works of national and international scholars to suggest modifications to in-service teacher training programmes. This paper consequently tries to present techniques of conducting CTE that are a combination of national and international experiences and suggests ways to implement this for foreign language teachers. It is hoped that the findings and outcomes of this project will be helpful in reaching the goals of the Conception.

\section{Review of the Literature}

A professional educator is always learning and honing their craft. They are on an endless journey where they are always looking for new ideas or teaching strategies, ways to improve their skills, or new information 
that will help their students to succeed. It takes a lot of hard work and effort to be a professional educator. "It requires effort to go that extra mile for the students who need it and it takes patience to continually grow and truly understand your craft as a teacher" (Cox, 2019).

The Organisation for Economic Co-operation and Development (OECD) adopts a broad definition of teachers' PD as "activities that develop an individual's skills, knowledge, expertise and other characteristics as a teacher" (2009, p. 49). Rose and Reynolds, citing Day, provide another definition of teachers' PD:

Professional development consists of all natural learning experiences and those conscious and planned activities which are intended to be of direct or indirect benefit to the individual, group or school, which contribute, through these, to the quality of education in the classroom. It is the process by which, alone and with others, teachers review, renew and extend their commitment as change agents to the moral purpose of teaching; and by which they acquire and develop critically the knowledge, skills and emotional intelligence essential to good professional thinking, planning and practice with children, young people and colleagues throughout each phase of their teaching lives (Day, 1999, p. 4, cited in: Rose \& Reynolds, n.d., p. 219).

\section{Methods of the Study}

This study aims at exploring EFL teachers' opinions of CPD and the CPD activities they engage in to develop professionally. Therefore, in attempting to investigate and interpret the meaning of CPD from the participants' perspectives within the researched context, the researcher is getting the benefits of a mixed method. Mixed method studies attempt to bring together qualitative and quantitative methods. In this mixed method study, the researcher conducted a series of semi-structured interviews with a small number of participants and also carried out a large-scale survey. This kind of integration of qualitative and quantitative methods helped the researcher to collect first-hand data for this project, which is the first of its kind.

\section{Participants}

Groups of both male and female teachers of English as a foreign language (TEFL) were selected by local education authorities and sent to central institutions. They teach at public schools all around the country, though 
their years of teaching experience are varied. As it is an ongoing study, the number of participants is increasing as groups are continuously coming and going after each two-week training seminar. They are graduates of higher education institutions and vocational education schools who have studied in and out of the country. The main reason for including such a wide selection of fresh and experienced full-time teachers is to be able to generate a broad range of perceptions, insights, and experiences of CPD.

\section{Data Collection}

The relevant data for this ongoing study is being collected directly from both male and female participants through informal interviews and surveys. The participants come to seminars, the duration of which is two weeks or two months. The sizes of the groups are from around twenty to twenty-five. These instruments help the researcher deeply explore EFL teachers' perspectives of CPD and the CPD activities they are engaged in. Hence, these instruments help to understand the problems beyond students' underperformance. As it is an ongoing study, the results will be published in a future paper.

\section{Aims and Objectives}

The cycle of in-service teacher training aims to enhance the professional and knowledge levels of the English language teachers in Turkmenistan through achieving the following objectives:

1. Exchange knowledge and professional experiences, opinions and findings, and discuss mechanisms of inspiring the performance level of teachers;

2. Inform the in-service English language teachers of the latest international publications in the fields of English language teaching and learning methods;

3. Present and follow the latest developments, modern technologies and leading practices in the field of English language education;

4. Highlight the importance of scientific research conducted by the researchers and academicians and enhance the overall performance of English teachers;

5. Guide self-development and develop English language education by using contemporary scientific methods and techniques; 
6. Promote a culture of innovation, openness, creativeness, novelty and leadership in English language teaching;

7. Train and inspire qualified personnel as regional English language trainers to work at local educational institutions and on the Train the Trainers programme.

\section{Research Questions}

A research project cannot be imagined without research questions. In order to reach the above-mentioned objectives, there are a set of research questions. The main research question of this project is English Language Teaching in Turkmenistan: Why? What? How? When? This is followed by various sub-questions that also need to be covered:

1. What is a good teaching method?

2. What is an effective teaching and learning process?

3. Do the teachers have a particular style or approach to teaching the English language?

4. What are the factors that make you unique as an English teacher?

5. What does a teacher expect from his/her students and vice versa?

6. What do teachers do for their CPD or CTE?

7. How often do English teachers use educational tools and technologies in their classes?

\section{How does the project operate?}

Keeping English as their working language, the following events are also planned to be held within the scope of the project:

1. Periodic workshops, seminars and training on various topics concerning teaching the English language for secondary school teachers based on a planned series of significant themes.

2. Seminars for English language instructors of higher education institutions.

3. Popularise the best papers and experiences through electronic and print publications.

4. Facilitate and strengthen the production of high-quality research from Turkmenistan relevant to the Turkmen ELT community.

5. Investigate and document current ELT theories and practices in Turkmenistan using full-bodied research. 
6. Facilitate and encourage the establishment and maintenance of active research links between ELT professionals and policy makers within Turkmenistan.

7. Exhibit the research and methodological publications related to English language teacher education.

The events of the project are open to future English language teachers too.

\section{What can this project offer to English language teachers?}

The professional development of English language teachers will take place through seminars and workshops throughout the project as well as national and international events with well-known speakers from both overseas and various parts of Turkmenistan. Throughout the project, the researcher will attend international teacher education and development conferences and other teacher training seminars, bring international experience to Turkmenistan and share it with Turkmen English language teachers. This project will provide a forum in which English language teachers can exchange ideas, share problems and find solutions to issues of classroom teaching. Finally, in an effort to unite all English language teachers working in secondary schools in Turkmenistan, our action plan must take into account opportunities that may arise to co-operate with other teachers that are not part of this project.

\section{Suggested Activities}

The following categories of activities are suggestions for meeting the needs of teachers' capacity building:

1. Collaborating with other teachers to examine case studies of student work and development;

2. Participating in courses and other learning opportunities;

3. Coursework linked to the improvement of instructional technique or content knowledge;

4. Coursework for more advanced certification;

5. Curriculum and materials planning and development;

6. Participating in formal programmes of peer coaching or participation in peer reviews; 
7. Participating in PD activities or other school-college teacher development partnerships;

8. Training to become an examination "assessor" or test development committee member.

\section{Preliminary Findings}

This project actively started in November 2019. A list of expected findings for in-service teacher training programme project has been systematically identified. These are:

1. To develop the competencies and skills needed for the professional development of teachers;

2. To enable them to organise competency-based and commitment-oriented professional programmes;

3. To enable them to develop pedagogy relevant to English language education;

4. To acquire an understanding of the needs and problems of teachers;

5. To develop skills related to classroom management;

6. To develop competencies of curriculum development and material preparation;

7. To develop their capacity for examination, analysis, interpretation, and communication of educational ideas;

8. To develop capabilities for self-directed and life-long learning;

9. To enable them to understand the relationship between local attitudes, modern technology and education;

10. To enable them to undertake meaningful educational research.

\section{Expected Implications}

The researcher would like to undertake this project as postdoctoral research work, and he can guide a few self-motivated, open-minded, research-oriented teachers who are curious and keen on professional development for their PhD studies. He also would like to use and document the gathered data as a postdoctoral dissertation.

Another target is to establish an Association of Turkmen English Language Teachers, which will undertake all activities related to English language teaching in provinces of the country. One more point is to organise national and international conferences where local and 
international experts and English language teachers can mingle, discuss related issues and share their valuable experiences.

\section{Research Limitations}

This teacher training project is an in-service training programme for English language teachers who are serving at public schools. For that reason, it is limited to school-level English language teachers. However, other foreign language teachers who are proficient in English may also attend and avail the benefits of the project.

\section{Action Plan}

The project's action plan summarises the steps which we will follow to answer the inquiry question(s) outlined in this study. The action plan makes it clear what needs to be done, who is doing what, and when these things will be done, as well as the costs. While it takes time to create, it ultimately saves time and guides us to achieve the goals we intended.

An action plan allows everyone involved to understand what we intend to do on a term-by-term basis. It enables us to keep track of what we are doing, to inform our checkpoint reporting and to respond to what we are learning. It is also a working document and can be modified if we find that a different course of action is likely to be more effective.

Within the framework of this action plan (see Annex 1), some schools would be selected as experimental and control groups. They would take part in this project with teachers, students and their teaching-learning processes. The feedback from teachers will help in preparing better strategies. The researcher, in the first step, will conduct surveys and tests under the general topic "Me and my English classes". There are language proficiency tests and teacher knowledge tests to check their educational background. Surveys will help to gather and interpret data on English language teaching.

\section{Conclusions and Recommendations}

In-service teacher training aims to improve the quality of teachers who are already engaged with teaching. This project, through in-service training programmes, aims to increase teachers' efficiency in public schools. It is expected that trained teachers will improve their English language teaching knowledge and skills, and it is also hoped that this 
improvement will raise the quality of English teaching at schools. Furthermore, teachers can change their classroom practices by providing more opportunities for students to actively engage in learning, which will result in better student learning. These expectations suggest that teacher training may be effective in improving student learning and that teachers' motivations may play a role in facilitating its effects. In the present study, through the preliminary findings, it has been illustrated that good teaching methods and techniques performed by teachers help students to question their preconceptions and motivate them to learn by putting them in a situation in which they come to see themselves as the authors of answers and the agents of responsibility for change and improvement.

The action plan for this project (see Annex 1) was planned for six terms, beginning with gathering additional information on the skills and knowledge that teachers have through test and questionnaires. It proposes workshop sessions on topics ranging from teachers' theoretical knowledge to skills in English language teaching. There are practical sessions on curriculum design and materials production. As this project is limited to English language teachers at public schools, there are some additional recommendations for them:

1. Develop abilities for evaluating educational programmes and designing learning materials;

2. Enable teachers to acquire the capability to organise in-service continuing education programmes;

3. Promote the global perspective of educational development with special reference to local situations;

4. Enable them to appreciate and adopt emerging communication technology and innovative practices in the local context;

5. Develop qualifications for EFL teachers who want to improve their English language teaching skills, knowledge and confidence;

6. Enable them to have a developed understanding of teaching methodology through assessed teaching practice;

7. Enable them to have a developed understanding of the principles underlying language learning and teaching;

8. Enable them to have the ability to identify learners' needs and monitor and evaluate their progress;

9. Enable them to have developed insights into and awareness of language form and function in the classroom; 
10. Organise periodic in-service training programmes for teachers, educational administrators, and other educational staff;

11. Prepare outlines and printed materials for local training programmes;

12. Participate in the preparation of textbooks, education materials, and educational programmes.

\section{References}

$\rightarrow$ Alibakhshi, G. and Dehvari, N. (2015). EFL teachers' perceptions of continuing professional development: A case of Iranian high school teachers, PROFILE Issues in Teachers' Professional Development, 17(2), 29-42.

$\rightarrow$ Bailey, K.M., Curtis, A. and Nunan, D. (2001). Pursuing professional development: The self as source. Boston: Heinle \& Heinle.

$\rightarrow$ Collins, A.B. (2010). English-medium higher education: Dilemma and problems, Eurasian Journal of Educational Research, 39, 97-110.

$\rightarrow$ Cox, J. (2019). Professional Development Tips for Teachers, www.teachhub. $\mathrm{com} /$ professional-development-tips-teachers

$\rightarrow$ OECD (2009). Creating Effective Teaching and Learning Environments: First Results from TALIS. Paris: Organisation for Economic Co-operation and Development, www.oecd.org/edu/school/43023606.pdf

$\rightarrow$ Rose, J. and Reynolds, D. (n.d.). Teachers' Continuing Professional Development: A New Approach, International Congress on Effectiveness and Improvement, 219-240.

\section{Annex 1}

\section{Provisional Action Plan}

Inquiry question: What is a good teaching method? What is an effective teaching and learning process? Do the teachers have a particular style or approach to teaching English? In what ways can teachers apply and practice new techniques in their classrooms to increase success? 


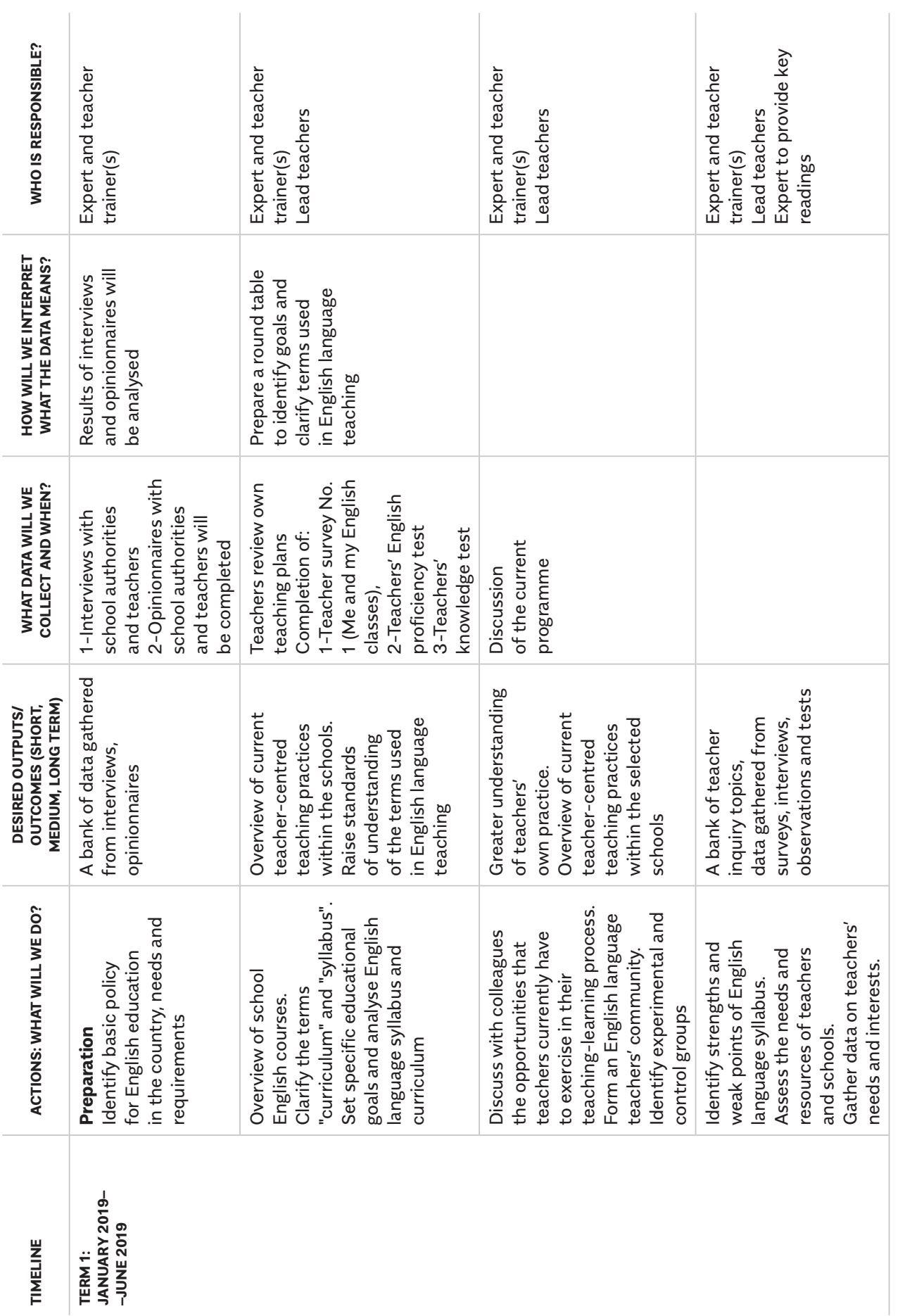




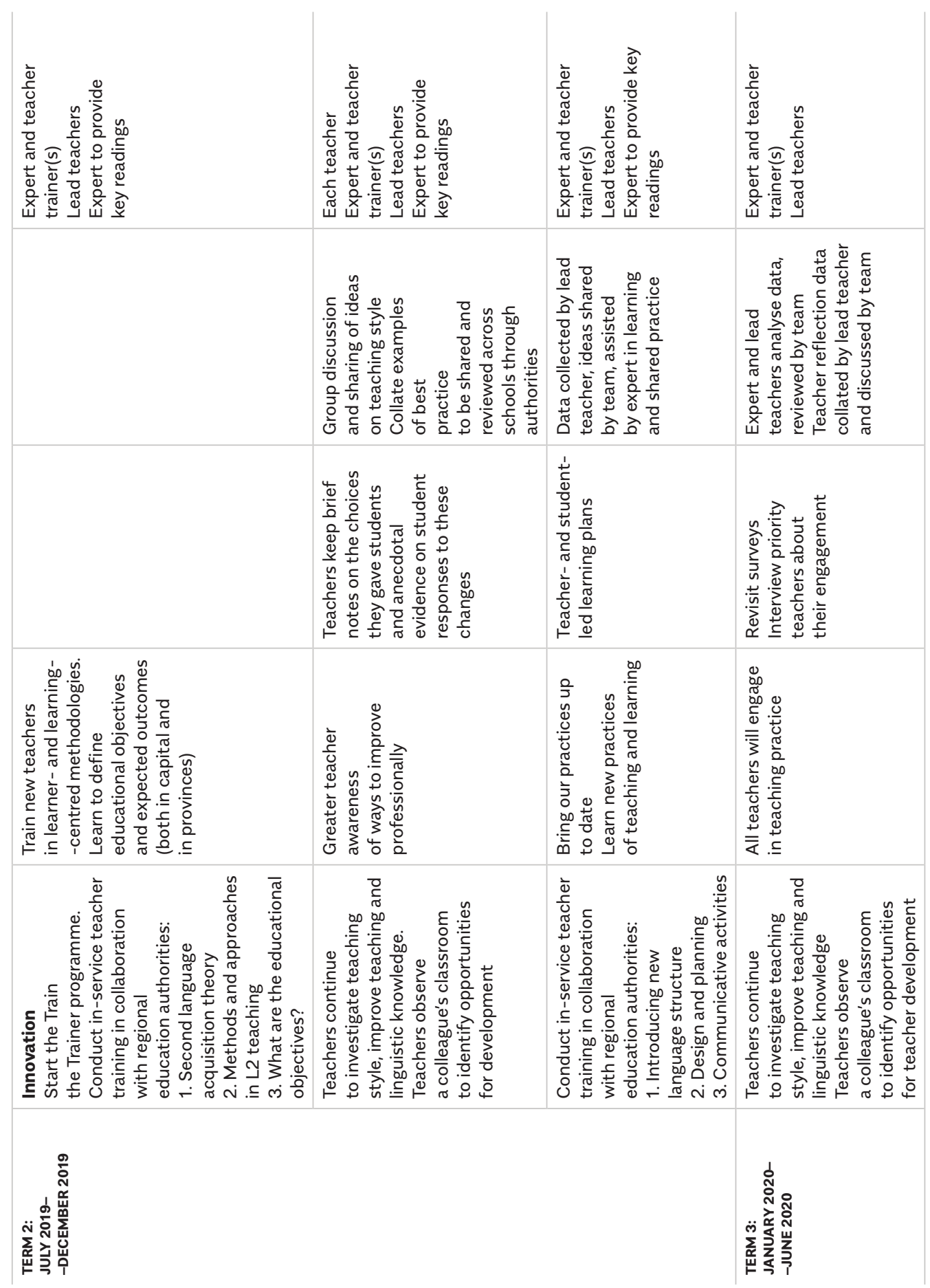




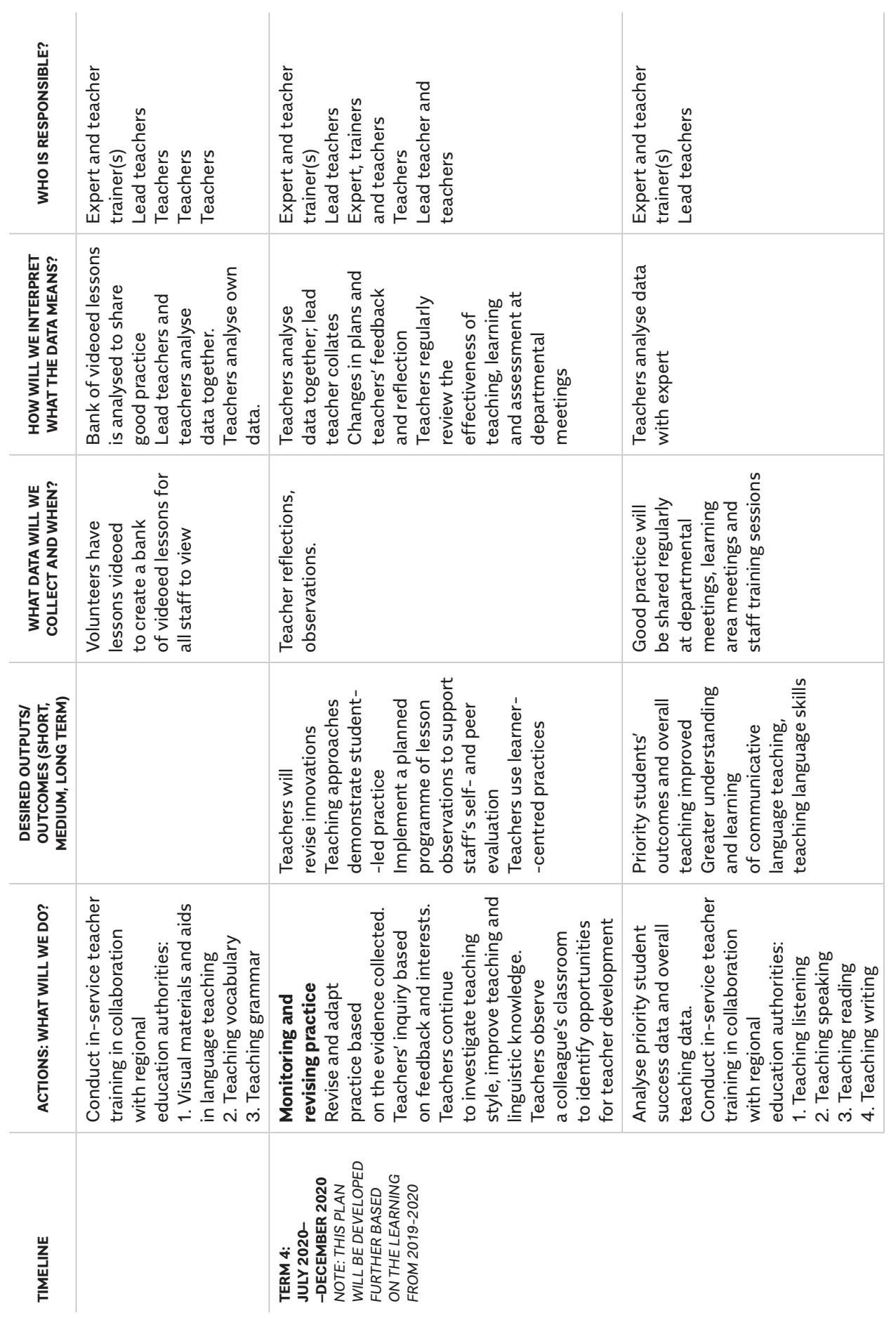




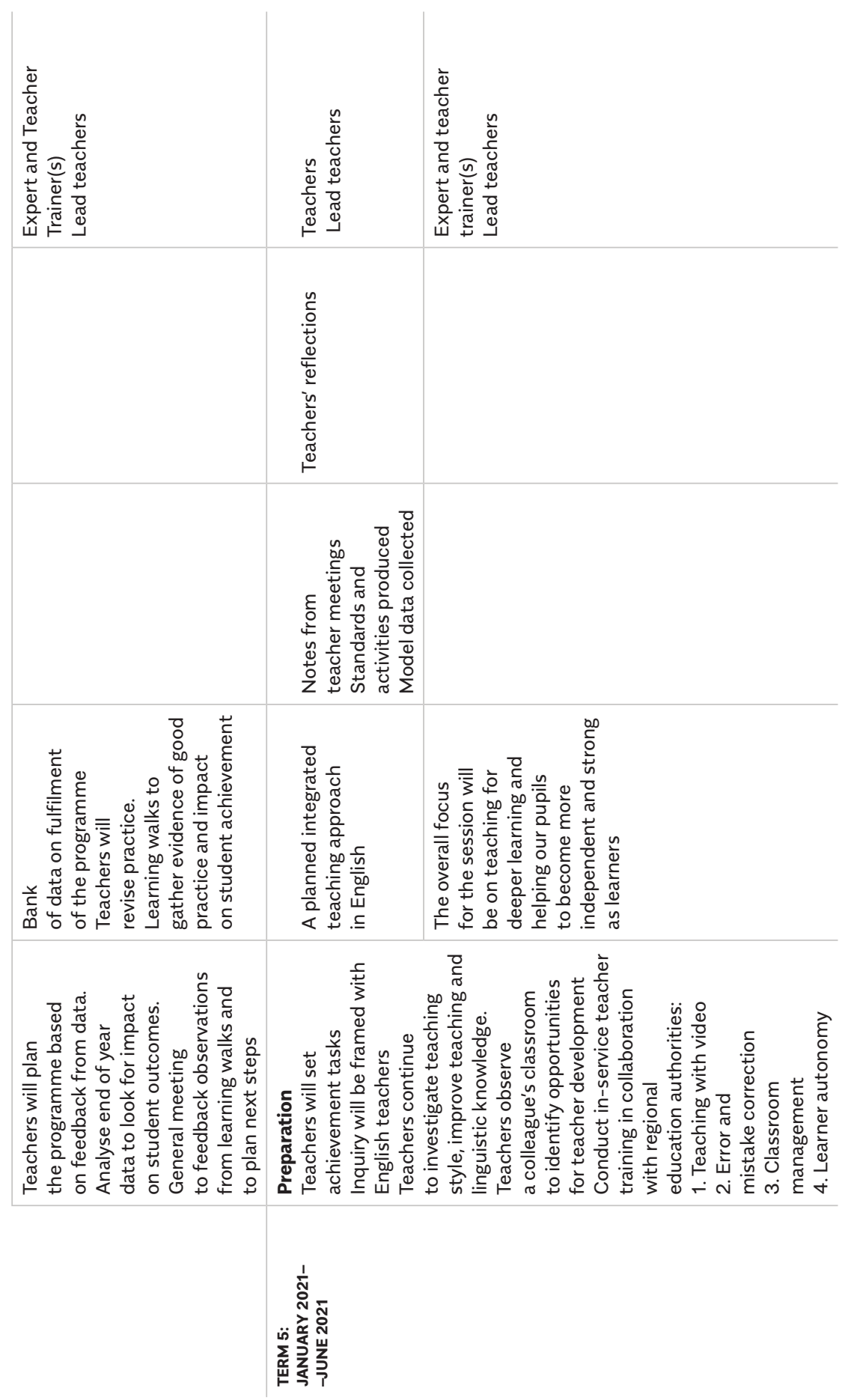




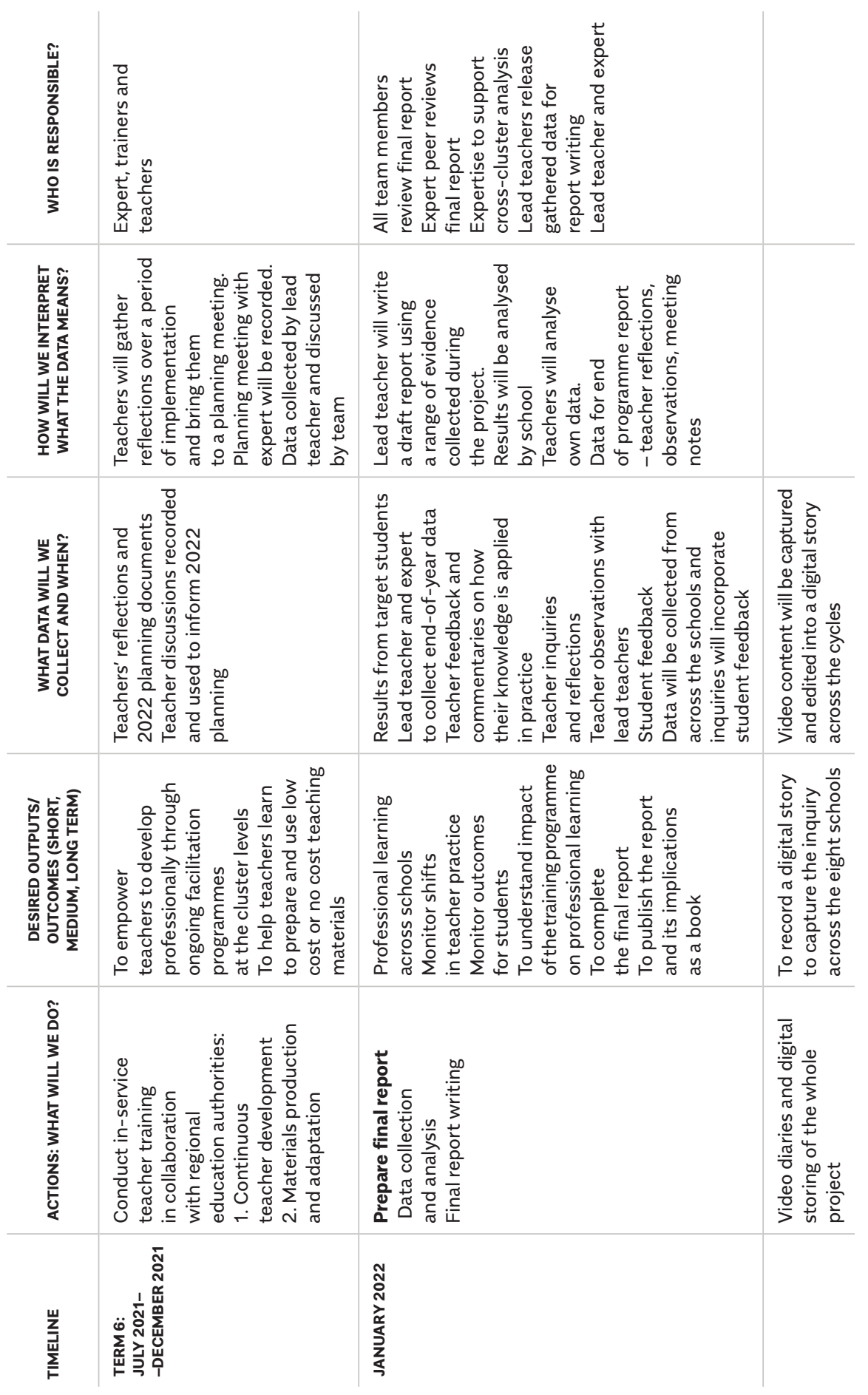

